\title{
The impact of organizational culture on supply chain integration in the hotel sector
}

Mahmoud Gebril Taha, Tomás F. Espino-Rodríguez and Antonia M. Gil-Padilla

\begin{abstract}
Purpose - Supply chain integration (SCI) has become a key strategy for hotels in facing their environment. The purpose of this study is to analyze the effects of the organizational culture on the three dimensions of SCl. The competing value framework divides the organizational culture into four types, namely, hierarchical, group, rational and developmental cultures.

Design/methodology/approach - A structural equations model was developed to test the hypotheses proposed. The data were collected by means of a questionnaire with a seven-point Likert-type rating scale that was distributed to managers and assistant managers of 114 four-or five-star hotels located in two Egyptian cities, Hurgada and Sharm El Sheikh.

Findings - The results of the structured model confirm the direct link between the organizational culture and SCl. The findings suggest that rational culture is the most appropriate for SCl because it is fully associated with SCl. In contrast, hierarchical culture and developmental culture are significantly related to internal and customer integration. Group culture only has a positive influence on internal integration.

Originality/value - This study is the first to analyze the impact of organizational culture on SCl in the hospitality sector. The results contribute to the literature by providing managers with practical knowledge about the significant influence of organizational culture on SCl.
\end{abstract}

Keywords Organizational culture, Supply chain integration, Competing value framework (CVF), Hotel sector

Paper type Research paper

\section{Introduction}

The extensive development of information technologies and the frequent changes in clients' needs have modified the concept of competition in the tourism sector because the greatest competition is focused on tourism supply chains rather than on individual companies (Zhang et al., 2009).

The hotel supply chain is based on the coordination of heterogeneous processes and activities and collaboration with all the entities to achieve mutual benefits (Zhang et al., 2009), which motivates managers to realign their internal and external resources to support the supply chain and establish long-term relationships with different parts of the supply chain. Therefore, supply chain integration $(\mathrm{SCl})$ has become an important element in achieving supply chain success.

In recent years, many researchers have studied SC (Cao et al., 2015), but there continues to be inconsistency in its definition and the best practices to implement it. This inconsistency makes it difficult for managers to identify key factors and practical solutions for SCl. In this context, previous studies have tried to identify some factors: information technology (Choi et al., 2008), organizational structure, relationships and organizational culture (Beth et al., 2003). These factors play an important role in the company's capacity and willingness to integrate internally and externally.
Mahmoud Gebril Taha, Tomás F. Espino Rodríguez and Antonia M. Gil-Padilla are all based at the Department of Economics and Business, University of Las Palmas de Gran Canaria, Las Palmas de Gran Canaria, Spain.

Received 15 April 2021 Revised 13 October 2021 24 October 2021

Accepted 26 October 2021 
Therefore, hotels seeking to achieve a higher level of external integration must have sufficient capabilities for SCl. These capabilities are reflected in the level of internal integration, the ability to communicate, the exchange of information and the mutual pursuit of better performance (Zhao et al., 2011). This inter-organizational alignment is determined by the hotel's organizational culture and it sometimes requires important changes in the mentality and culture of supply chain members (Braunscheidel et al., 2010). In this regard, $\mathrm{SCl}$ can be viewed as linking multiple business cultures (Cao et al., 2015). Therefore, the organizational culture plays a key role in SCI (Braunscheidel et al., 2010).

The organizational culture represents the values and beliefs shared by the members of the company (Braunscheidel et al., 2010), which not only directly affect the employees' behavior but also the company's relationships and behavior toward its external environment. Thus, the organizational culture provides skills such as trust, relationship development and information sharing, which are important aspects of SCl success.

Many investigations in the literature have individually studied organizational culture or SCI and their impact on company performance and outcomes (Flynn et al., 2010; Zhao et al., 2011). Despite this abundant literature, research analyzing the relationship between organizational culture and SCl is scarce (Braunscheidel et al., 2010) and all are in the manufacturing sectors. Although in the hotel sector there is no study that analyzes the impact of organizational culture on $\mathrm{SCl}$.

In the literature on the relationships between the organizational culture and $\mathrm{SCl}$, the results of these studies have not been consistent, even though similar definitions have been used. For example, Braunscheidel et al. (2010) and Zu et al. (2010) show that rational culture has a positive influence on external integration. In contrast, Cao et al. (2015) find that rational culture is positively related to internal integration. Braunscheidel et al. (2010) find that group culture is not associated with external integration. In contrast, Cao et al. (2015) and Porter (2019) find that group culture positively influences both internal and external integration.

These inconsistent results motivate us to carry out this study in the hotel sector, compare the results with other sectors and try to understand the relationships between organizational culture and $\mathrm{SCl}$ in different sectors. In this context, studying the relationship between organizational culture and $\mathrm{SCl}$ within the hotel context is of great importance because it can help industry professionals to adopt the correct culture and best practices for successful $\mathrm{SCl}$, especially in these post-Covid-19 times, which affected the hotel sector. Hotels have had to change many cultural aspects to follow safety protocols, in addition to altering the ways they manage their supply chains. This crisis may motivate hotels to turn more to $\mathrm{SCl}$ to reduce costs and understand customer needs. Therefore, in the coming years, the hotel industry will have to work hard to redesign its supply chains according to the needs and circumstances that arise.

The goal of this study is to analyze the influence of the organizational culture presented in the competing values framework (CVF) on SCl in the context of the hotel sector, given that this study is one of the first to analyze these relationships in the hotel sector. To achieve this goal, a questionnaire was presented to the directors and managers of 114 four- and fivestar hotels in the Egyptian hotel sector. The theoretical framework and hypothesis development are presented below, followed by the analysis of the results. Finally, the conclusions are presented, including the academic and practical implications and recommendations for future research.

\section{Literature review}

\subsection{Supply chain integration}

According to Porter (2019), a lack of consistent findings and limited empirical evidence in

the $\mathrm{SCl}$ literature make it difficult to have a solid set of $\mathrm{SCl}$ definitions, dimensions and 
guidelines. The literature contains several definitions of the $\mathrm{SCl}$ concept. In this study, we adopt the definition by Zhao et al. (2008), which states that SCI refers to the degree to which an organization collaborates strategically with supply chain partners and orients intra- and inter-organizational processes toward achieving an efficient and effective flow of information about products, services, money and decisions, to provide maximum value for its customers.

Researchers currently classify SCI into three main categories: internal integration (II), supplier integration (SI) and customer integration (Cl) (Zhao et al., 2011).

Internal integration is defined as the strategies and practices that facilitate coordination and cooperation in the management of information, processes and joint decision-making among departments within a company (Braunscheidel et al., 2010). Communication and coordination allow information sharing across employees and departments, facilitate decision-making, improve production flexibility (Cao et al., 2015). According to Zhao et al. (2011), internal integration is the basis for external integration and the first step in achieving it.

Supplier integration refers to a company's strategy of associating and collaborating with its suppliers to manage inter-organizational activities to exchange information and participate in decision-making and production (Cao et al., 2015).

Customer integration refers to the collaboration between a company and its customers (Zhao et al., 2011). These relationships provide the hotel with knowledge about their needs and their expectations for products and services, to take them into account in the work processes, product production phases and decision-making.

Therefore, for hotels, $\mathrm{SCl}$ is a strategy to improve company performance (Dragan et al., 2015). This strategy allows companies to reduce costs, increase flexibility, improve the quality of products or services, maximize customer satisfaction and, therefore, create competitive advantages (Cao et al., 2015; Porter, 2019). Despite these advantages, SCl implementation is difficult and costly, given that it requires companies to make some organizational changes, such as adopting or improving capabilities and investing heavily in partner relationships, which are often complicated and risky (Cao et al., 2015). For the successful implementation of $\mathrm{SCl}$, companies must first improve their internal integration through efficient processes and operations planning, followed by their external integration (Porter, 2019).

\subsection{Organizational culture}

According to Cameron and Quinn (2011), organizational culture is closely related to companies' effectiveness. In this regard, Tepeci and Bartlett (2002) pointed out that, in the hotel industry, organizational culture has significant implications for organizational performance and employees' values and behavior. Therefore, organizational culture determines the ways employees work and it differs from one hotel to another.

The organizational culture represents the values and beliefs shared by the members of the company (Braunscheidel et al., 2010), which directly affects the behaviors of employees within an organization and the hotel's policies toward its external environment. To measure organizational culture, we adopted Cameron and Quinn's CVF (2011), the most widely used model in empirical studies (Porter, 2019). According to Cameron and Quinn (2011), this framework is based on two dimensions: the first presents "control-flexibility" in terms of the degree to which an organization can focus on stability in the face of change. The second dimension, "internal-external," indicates the organization's orientation toward its environment, considering the internal versus external environment.

These two dimensions make it possible to identify four types of organizational culture: hierarchical culture (internal positioning and control approach), group culture (internal 
positioning and flexibility approach), rational culture (external positioning and control approach) and developmental culture (external positioning and flexibility approach).

\section{Hypotheses development}

\subsection{Hierarchical culture and supply chain integration}

The hierarchical culture is oriented toward uniformity and predictability, in both activities and people, as well as process improvement, internal efficiency and stability (Cameron and Quinn, 2011). Companies oriented toward this culture usually have a highly formalized and structured workplace where daily activity is governed by clearly defined procedures and employees must follow strict rules and regulations to solve problems, coordinate with each other and formalize decision-making structures (Zu et al., 2010).

Despite these advantages, hierarchical culture can have a negative influence on SCI for two reasons. First, hierarchical culture has a mentality of independent departmental functions, that is, a separation of functions, which is an obstacle to achieving internal integration and to share responsibilities and exchange information with supply chain partners (Cao et al., 2015), a fundamental element of SCl.

Second, employees of firms oriented toward hierarchical culture are accustomed to only following the procedures and standards prescribed in their tasks and they can be reluctant to change (Cao et al., 2015). In addition, this culture makes it difficult for the participation of employees in work processes, decision-making or search for solutions to problems. Therefore, this culture hinders $\mathrm{SCl}$ or only allows its limited implementation (Cao et al., 2015). Similarly, the study by Braunscheidel et al. (2010) and Cao et al. (2015) finds a negative influence of the hierarchical culture on both internal and external integration. For this reason, the following hypotheses are proposed:

H1a. Hierarchical culture has a negative influence on internal integration.

H1b. Hierarchical culture has a negative influence on supplier integration.

H1c. Hierarchical culture has a negative influence on customer integration.

\subsection{Group culture and supply chain integration}

Group culture has an internal focus and is characterized by teamwork, members' participation in the organization and increasing employees' capabilities and knowledge (Cameron and Quinn, 2011). These values of collaboration and participation are essential in implementing $\mathrm{SCl}$, which often requires mutual cooperation among supply chain members on work processes and problem-solving (Flynn et al., 2010).

Furthermore, the strategy of this culture emphasizes human relations within the organization by strengthening mutual trust among its members, exchanging information and knowledge and sharing experiences, thus reducing conflicts, improving the quality of products and services and achieving the objectives established by the organization (Zhao et al., 2008). Therefore, these values are essential for successful internal integration.

In addition, this atmosphere of cooperation among hotel members facilitates the development of relationships with both suppliers and customers and it motivates employees to exchange information and knowledge with these partners, which is beneficial for customer integration and supplier integration (Naor et al., 2008). Furthermore, Cao et al. (2015) suggest the positive impact of group culture on both internal and external integration. For this reason, the following hypotheses are proposed:

H2a. Group culture has a positive influence on internal integration.

H2b. Group culture has a positive influence on supplier integration. 
H2c. Group culture has a positive influence on customer integration.

\subsection{Rational culture and supply chain integration}

Rational culture, which has an external focus, is oriented toward planning, efficient use of resources and competitiveness to reach the predefined objectives of the organization (Naor et al., 2008). At the same time, this culture emphasizes control and stability, which means using certain resources and strategies to achieve goals. Therefore, managers in companies motivate employees to devote time and resources to perform their tasks to the best of their ability and they emphasize collaboration among hotel members to achieve defined objectives. In addition, this culture is characterized by the use of incentives and rewards as tools to maximize employees' participation and develop their capabilities and skills, leading to higher quality and competitive advantage (Noar et al., 2008). In this regard, the study by Cao et al. (2015) shows the positive impact of rational culture on internal integration.

On the other hand, communication and relations with the hotel's external environment are important to achieve the aims of rational culture. Establishing close relationships with customers and suppliers is the main way to reach a competitive position that is considered a fundamental element of rational culture (Naor et al., 2008). Therefore, hotels oriented toward this culture must make an effort to establish close and long-term relationships and collaboration with customers and suppliers to create customized products and services, improve productivity and create competitive advantages. In this context, the studies by Braunscheidel et al. (2010) and Zu et al. (2010) find a significant and positive relationship between rational culture and both supplier and customer integration. Based on the above, the following hypotheses are proposed:

H3a. Rational culture has a positive influence on internal integration.

H3b. Rational culture has a positive influence on supplier integration.

H3c. Rational culture has a positive influence on customer integration.

\subsection{Developmental culture and supply chain integration}

Developmental culture emphasizes the external environment to maximize flexibility, improve structure and learning and adapt to changes in the life of the company (Noar et al., 2008). This culture focuses on achieving long-term objectives through the use of strategies such as innovation, the acquisition of new resources and the creation of new markets and challenges (Cameron and Quinn, 2011). In this regard, SCl is a tool for creating long-term value and so there is likely to be a close relationship between developmental culture and successful SCl.

Moreover, this culture allows hotels to be more flexible and dynamic and adapt to changing demands and customer needs (Naor et al., 2008). This flexible and dynamic environment motivates employees to develop their skills and abilities, adapt to new opportunities and demands and look for creative solutions to both internal and external problems.

With regard to external integration, hotels oriented toward this culture have to build close relationships with their suppliers and customers to develop their innovative capabilities, innovate new services based on customer needs and expectations, obtain reliable information about products, markets and the necessary technologies. In this regard, external suppliers' participation is increasingly important because hotels need to complement their capabilities. In this context, Braunscheidel et al. (2010) and Cao et al. (2015) find a positive impact of developmental culture on supplier and customer integration. Based on the above, the following hypotheses are proposed:

H4a. Developmental culture has a positive influence on internal integration.

H4b. Developmental culture has a positive influence on supplier integration. 
H4c. Developmental culture has a positive influence on customer integration.

These hypotheses are represented in the conceptual model shown in Figure 1.

\section{Methodology}

\subsection{Area of research and sample}

The tourist destination chosen for the research is Egypt because it is considered a solid and competitive destination with a wide variety of tourist activities. Egypt received a number of visitors in 2019, with 13.6 million tourists, producing revenues of 12.5bn dollars (CAPMAS, 2019). Due to the Covid-19 pandemic, this number declined to 3.5 million tourists in 2020 , generating revenue of $4 \mathrm{bn}$ dollars (Reuters, 2020). The hotel sector is considered a powerful sector because it has 205,000 rooms (Reuters, 2020) in different types of hotels. According to World Travel and Tourism Council statistics (Mordorintelligence, 2020), the average revenue per room increased by almost 12.9\% in 2019, compared to 2018, whereas the overall occupancy increased by $6.5 \%$ and the average daily revenue grew by $6.2 \%$, registering at 1,290 Egyptian pounds for 2019.

Within this broad destination, we concentrated our research on four- and five-star sun and beach hotels in two tourist cities, Sharm El Sheikh and Hurghada. These two cities were selected because, along with Cairo, which only has urban or city hotels, they are the most popular tourist destinations in Egypt and they have most of the accommodation supply. they have a diversified tourism offering and so they are considered ideal populations for our study. In addition, we have used this star rating because research shows that these companies have strong and proactive work systems (El Houshy et al., 2019), which can ensure the use of SCI practices.

The total number of registered hotel establishments is 149, according to the Egyptian Hotel Sector Association. These 149 hotels are distributed in the following way: in Sharm El Sheikh, there are 93 hotels and in Hurgada, there are 56 hotels. Of the entire study population of 149 hotels, 114 hotels participated in the study because the rest declined to participate. The 114 hotels are distributed in the following way: in Sharm El Sheikh, 72 hotels

\section{Figure 1 Conceptual model and hypotheses}

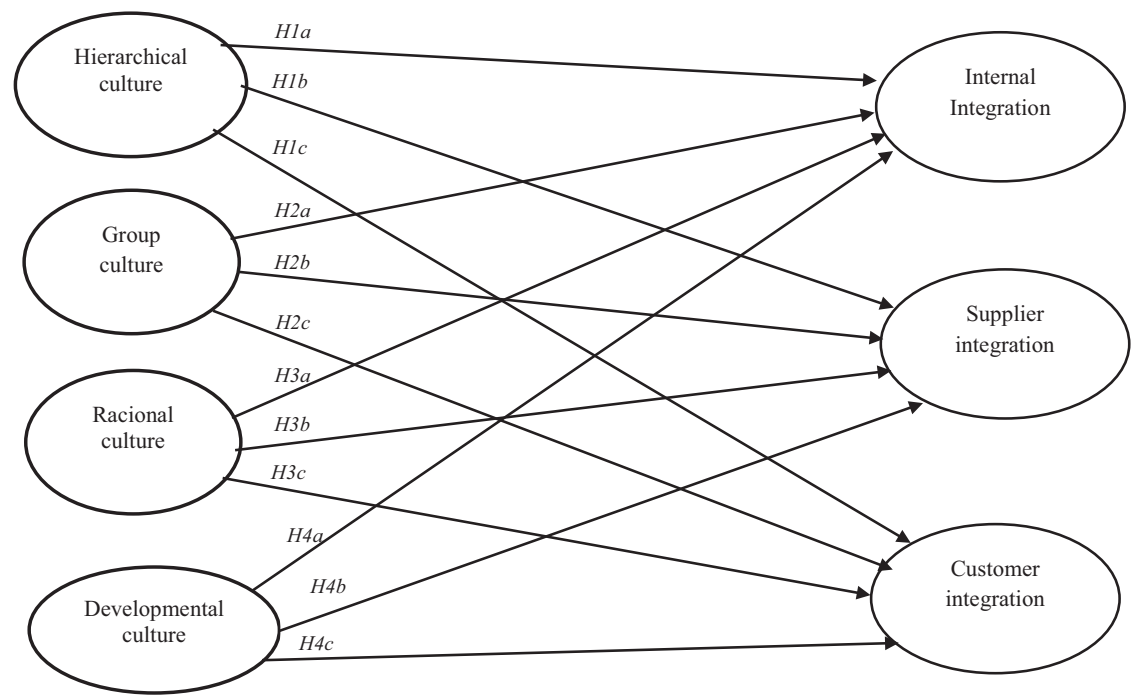


participated (45 5-star and 27 4-star establishments) and in Hurgada, 42 hotels participated (26 5-star and 16 4-star establishments). Thus, we obtained an actual participation rate of $76.5 \%$.

The researcher made appointments with the hotels to administer the questionnaire. The respondents are the general managers or assistant managers because they have enough information and knowledge to answer the questionnaire. However, at times it was not possible to make appointments with them and so the researcher held the interview with the department heads, who sometimes contacted the managers of other departments when they did not know the answer to a question. Of the total respondents, 28 general managers, 59 assistant managers and 28 department heads were interviewed. The original questionnaire was written in Spanish and translated into Arabic and was carried a pilot test.

\subsection{Measurement of the variables}

To increase the reliability and validity of the survey in this study, previously developed and validated scales with a seven-point Likert scale are used, where 1 indicates strongly disagree and 7 indicates strongly agree. The questionnaire is composed of two constructs: organizational culture and $\mathrm{SCl}$.

To measure organizational culture, which is divided into four types: hierarchical culture, group culture, rational culture and developmental culture, five-item scales were used for each type. The items that measure these constructs were taken from the studies by Gambi et al. (2015). These constructs involve questions related to the specificities of each culture, such as the degree of control; communication between employees; planning and competitiveness to achieve the objectives; and, finally, the use of technologies and innovation.

SCl was measured using the scales found in Cao et al. (2015) SCl is divided into three dimensions: internal integration, supplier integration and customer integration, which were measured with 6-, 7- and 6-item scales, respectively. These scales measure the degree of coordination and collaboration within the hotel, the level of collaboration between the hotel and its suppliers and customers.

Harman's one-factor test for common method bias using exploratory factor analysis with SPSS 26.00 indicates that one factor explains only $24.92 \%$ of the variance, which is clearly below the cut-off point of $50 \%$ (Podsakoff, 2003). This shows that common method bias was not a significant issue in this study.

\section{Results}

To test the research hypotheses and analyze the predictive power of the model, we used the partial least squares (PLS) technique through the Smart PLS 3.2.8 program (Ringle et al., 2018). The objective of PLS-structural equation modeling (SEM) models is more related to prediction than to confirmation. The SEM-PLS technique is mainly used for the theoretical development of exploratory research (Ringle et al., 2018). PLS provides more robust model estimates for smaller sample sizes than methods based on covariance models. Thus, this technique is less demanding and more flexible with regard to requirements and sample size.

\subsection{Measurement model}

The measurement model aims to assess:

- individual reliability of the indicator and the construct;

- convergent validity and 
- discriminant validity (Fornell and Larcker, 1981; Tenenhaus et al., 2005).

The reliability of each indicator consists of evaluating the factorial loads of the items in their respective constructs. Hair et al. (2017) found that the recommended threshold was 0.707 , but Tenenhaus et al. (2005) indicate that items with a load of more than 0.5 are acceptable. The data in Table 1 show that the item loadings exceed the threshold of 0.5 and are significant.

On the one hand, to evaluate reliability, composite reliability (CR) and Cronbach's alpha were used. Both measures should have a recommended value of more than 0.7 (Fornell and Larcker, 1981). The results in Table 1 indicate that the composite reliability values range between 0.865 and 0.932, whereas Cronbach's alphas range between 0.765 and 0.909 , confirming that the scales are reliable. On the other hand, convergent validity is measured by means of the average variance extracted (AVE) of each construct and requires a recommended value equal to or greater than 0.5 (Fornell and Larcker, 1981). The results indicate that the values obtained range between 0.576 and 0.733 , which shows that the model has convergent validity.

To evaluate discriminant validity, we use the Fornell-Larcker criterion and the HeterotraitMonotrait ratio (HTMT) correlations. In this context, as Table 2 shows, the square root of the

Table 1 Evaluation of the measurement model. Reliability and construct validity

\begin{tabular}{|c|c|c|c|c|c|c|}
\hline Variables & Factors & tor loao & $T$ & Alfa de Cronbach & Composite reliability & AVE \\
\hline Hierarchical culture & HC_1 & 0.813 & 25.869 & 0.765 & 0.865 & 0.681 \\
\hline$(\mathrm{HC})$ & HC_2 & 0.800 & 22.223 & & & \\
\hline & HC_3 & 0.861 & 31.257 & & & \\
\hline Group culture & GC_1 & 0.804 & 25.677 & 0.847 & 0.897 & 0.686 \\
\hline$(\mathrm{GC})$ & GC_2 & 0.814 & 25.491 & & & \\
\hline & GC_3 & 0.870 & 30.560 & & & \\
\hline & GC_4 & 0.823 & 22.773 & & & \\
\hline Rational culture & $\mathrm{RC} \_1$ & 0.729 & 16.079 & 0.859 & 0.899 & 0.643 \\
\hline$(\mathrm{RC})$ & RC_2 & 0.695 & 12.748 & & & \\
\hline & RC_3 & 0.897 & 55.037 & & & \\
\hline & $\mathrm{RC} \_4$ & 0.821 & 30.326 & & & \\
\hline & RC_5 & 0.849 & 28.690 & & & \\
\hline Developmental culture & DC_1 & 0.854 & 42.825 & 0.907 & 0.931 & 0.730 \\
\hline$(\mathrm{DC})$ & DC_2 & 0.781 & 21.170 & & & \\
\hline & DC_3 & 0.881 & 45.526 & & & \\
\hline & DC_4 & 0.881 & 45.605 & & & \\
\hline & DC_5 & 0.871 & 40.113 & & & \\
\hline Internal integration & II_1 & 0.829 & 32.034 & 0.909 & 0.932 & 0.733 \\
\hline (II) & II_2 & 0.873 & 41.305 & & & \\
\hline & II_3 & 0.826 & 27.132 & & & \\
\hline & II_4 & 0.885 & 44.217 & & & \\
\hline & II_5 & 0.866 & 39.129 & & & \\
\hline Supplier integration & SI_1 & 0.664 & 5.311 & 0.891 & 0.904 & 0.576 \\
\hline$(\mathrm{SI})$ & SI_2 & 0.760 & 9.829 & & & \\
\hline & SI_3 & 0.862 & 15.639 & & & \\
\hline & SI_4 & 0.852 & 12.702 & & & \\
\hline & SI_5 & 0.800 & 9.217 & & & \\
\hline & SI_6 & 0.703 & 5.983 & & & \\
\hline & SI_7 & 0.641 & 4.740 & & & \\
\hline Customer integration & $\mathrm{Cl}_{-} 1$ & 0.773 & 21.643 & 0.887 & 0.917 & 0.690 \\
\hline$(\mathrm{Cl})$ & Cl_2 & 0.878 & 40.953 & & & \\
\hline & $\mathrm{Cl} \_3$ & 0.853 & 32.901 & & & \\
\hline & Cl_4 & 0.809 & 21.820 & & & \\
\hline & Cl_5 & 0.836 & 29.106 & & & \\
\hline
\end{tabular}


AVE (main diagonal) is higher than the correlations between the constructs in all cases, which suggests that all the constructs are valid measures of unique concepts.

With regard to the HTMT, the inference test was used. Table 3 shows the $95 \%$ confidence intervals of the HTMT values. The results reveal that none of the intervals include 1 , indicating that there is discriminant validity (Henseler et al., 2015).

\subsection{Structural model}

After confirming the reliability and validity of the measurement model, we evaluated the structural model. As in Hair et al. (2017), non-parametric Bootstrap resampling with 500 repetitions was performed to obtain the explained variance $\left(R^{2}\right)$, the $f^{2}$ effect and the standardized Path coefficients $(\beta)$ of each of the predicted relationships in the model's hypotheses with the observed $t$ values. The fit of the structural model was composed of the $R^{2}$ that represents the explained variance of the dependent variables. For Falk and Miller (1992), these values have to be above the threshold of 0.1. As Table 4 shows, internal

\section{Table 2 Discriminant validity and the Fornell-Larcker criterion}

\begin{tabular}{lccccccc} 
Variables & $H C$ & $G C$ & $R C$ & $D C$ & $I I$ & $S I$ & $C l$ \\
\hline Hierarchical culture & 0.825 & & & & & & \\
Group culture & 0.709 & 0.828 & & & & & \\
Rational culture & 0.724 & 0.786 & 0.802 & & & & \\
Developmental culture & 0.750 & 0.812 & 0.792 & 0.854 & & & \\
Internal integration & 0.726 & 0.722 & 0.721 & 0.733 & 0.856 & & \\
Supplier integration & 0.286 & 0.341 & 0.433 & 0.315 & 0.261 & 0.759 & \\
Customer integration & 0.784 & 0.712 & 0.797 & 0.783 & 0.825 & 0.283 & 0.831
\end{tabular}

Note: Diagonal elements (italics values) are the square root of the AVE

\section{Table 3 Discriminant validity: Heterotrait-monotrait ratio (HTMT) of 5\% and 95\% confidence intervals}

\begin{tabular}{|c|c|c|c|c|c|c|}
\hline Variables & $H C$ & $G C$ & $R C$ & $D C$ & /I & SI \\
\hline Hierarchical culture & & & & & & \\
\hline Group culture & $(0.783 ; 0.962)$ & & & & & \\
\hline Rational culture & $(0.814 ; 0.952)$ & $(0.866 ; 0.957)$ & & & & \\
\hline Developmental culture & $(0.815 ; 0.965)$ & $(0.867 ; 0.974)$ & $(0.834 ; 0.936)$ & & & \\
\hline Internal integration & $(0.784 ; 0.945)$ & $(0.748 ; 0.884)$ & $(0.730 ; 0.879)$ & $(0.712 ; 0.872)$ & & \\
\hline Supplier integration & $(0.186 ; 0.455)$ & $(0.203 ; 0.508)$ & $(0.297 ; 0.541)$ & $(0.200 ; 0.421)$ & $(0.171 ; 0.420)$ & \\
\hline Customer integration & $(0.886 ; 0.950)$ & $(0.739 ; 0.877)$ & $(0.845 ; 0.953)$ & $(0.796 ; 0.919)$ & $(0.870 ; 0.950)$ & $(0.198 ; 0.419)$ \\
\hline
\end{tabular}

\section{Table 4 GoF (index)}

\begin{tabular}{llll} 
Variables & AVE & $R^{2}$ & $Q^{2}$ \\
\hline Hierarchical culture & 0.681 & & \\
Group culture & 0.686 & & \\
Rational culture & 0.643 & & \\
Developmental culture & 0.730 & 0.643 & 0.435 \\
Internal integration & 0.733 & 0.191 & 0.074 \\
Supplier integration & 0.576 & 0.744 & 0.473 \\
Customer integration & 0.690 & 0.356 & \\
AVE $\times R^{2}$ & & 0.597 & \\
GoF $=\sqrt{ }$ AVE $\times R^{2}$ & & &
\end{tabular}


integration explains $64.3 \%\left(R^{2}=0.643\right)$, supplier integration explains $19.1 \%\left(R^{2}=0.191\right)$ and customer integration explains $74.4 \%\left(R^{2}=0.744\right)$ of the variance in the four types of organizational culture. Therefore, these results confirm that the model has the predictive capability.

While $R^{2}$ measures predictive capacity, $Q^{2}$ measures predictive relevance. All $Q^{2}$ values are expected to be positive (Hair et al., 2017). Table 4 shows that all $Q^{2}$ values are greater than zero, ranging from 0.074 to 0.473 and so the model has predictive relevance. In relation to the goodness of fit (GoF), Hair et al. (2017) indicate that models that achieve a value greater than 0.36 are considered good-fitting models. In our case, the value of the GoF is 0.597 (Table 4), which suggests a good fit.

With regard to the size of the $f^{2}$ effect Cohen (1988) indicates that the $f^{2}$ values have to be above the recommended threshold of 0.02 . As Table 5 shows, most of the $\mathrm{f}^{2}$ effects obtained from the significant variables are higher than the base level of 0.02 .

Finally, standardized path coefficients $(\beta)$ are used to test the importance and contrast the hypotheses. As Table 5 and Figure 2 show, hierarchical culture has a positive influence on internal integration ( $\beta=0.298, p<0.01)$ and customer integration $(\beta=0.350, p<0.001$ ), therefore, $\mathrm{H} 1 \mathrm{a}$ and $\mathrm{H} 1 \mathrm{C}$ are not supported. However, does not significantly influence customer integration ( $H 1 b)(\beta=-0.043, p>0.05)$ and so it is not supported either.

Regarding $\mathrm{H} 2$, the results are mixed because there is a positive relationship between group culture and internal integration ( $\beta=0.298, p<0.01$ ), confirming H2a. However, the relationships between group culture and supplier integration and customer integration are not significant and so $\mathrm{H} 2 \mathrm{~b}$ and $\mathrm{H} 2 \mathrm{c}$ are not accepted $(\beta=0.060, p>0.05 ; \beta=-0.033$, $p>0.05)$.

As for $H 3 a, H 3 b$ and $H 3 c$, the results indicate that there is a positive relationship between rational culture and the three types of integration ( $\beta=0.196, p<0.05 ; \beta=0.485, p<0.01$; $\beta=0.366, p<0.001)$. Therefore, $H 3 a, H 3 b$ and $H 3 c$ are supported.

As for $\mathrm{H} 4 \mathrm{a}$, the results show a positive and significant, but weak, relationship at $10 \%$ significance between developmental culture and internal integration ( $\beta=0.189, p<0.09$ ). Therefore, $\mathrm{H} 4 \mathrm{a}$ is moderately supported. With regard to $\mathrm{H} 4 \mathrm{C}$, it is supported because there is a positive relationship between developmental culture and customer integration ( $\beta=$ $0.257, p<0.01)$. The results indicate that developmental culture does not significantly influence supplier integration ( $\beta=-0.086, p>0.05$ ). Therefore, $H 4 b$ is not supported.

Table 5 Path coefficients, $t$-statistics and $F$-squared

\begin{tabular}{lrrrrr} 
Hypothesis & $B$ & $t$ & $p$ & $f$ & Outcome \\
\hline Hierarchical culture $\rightarrow$ internal integration & 0.298 & 3.038 & 0.001 & 0.095 & Not supported \\
Hierarchical culture $\rightarrow$ supplier integration & -0.043 & 0.258 & 0.398 & 0.001 & Not supported \\
Hierarchical culture $\rightarrow$ customer integration & 0.350 & 4.089 & 0.000 & 0.183 & Not supported \\
Group culture $\rightarrow$ internal integration & 0.203 & 1.773 & 0.038 & 0.032 & Supported \\
Group culture $\rightarrow$ supplier integration & 0.060 & 0.270 & 0.393 & 0.001 & Not supported \\
Group culture $\rightarrow$ customer integration & -0.033 & 0.358 & 0.360 & 0.001 & Not supported \\
Rational culture $\rightarrow$ internal integration & 0.196 & 1.833 & 0.034 & 0.031 & Supported \\
Rational culture $\rightarrow$ supplier integration & 0.485 & 2.732 & 0.003 & 0.085 & Supported \\
Rational culture $\rightarrow$ customer integration & 0.366 & 3.884 & 0.000 & 0.154 & Supported \\
Developmental culture $\rightarrow$ internal integration & 0.189 & 1.920 & 0.099 & 0.025 & Supported \\
Developmental culture $\rightarrow$ supplier integration & -0.086 & 0.426 & 0.335 & 0.002 & Not supported \\
Developmental culture $\rightarrow$ customer integration & 0.257 & 2.662 & 0.004 & 0.065 & Supported
\end{tabular}




\section{Figure 2 Structural model}

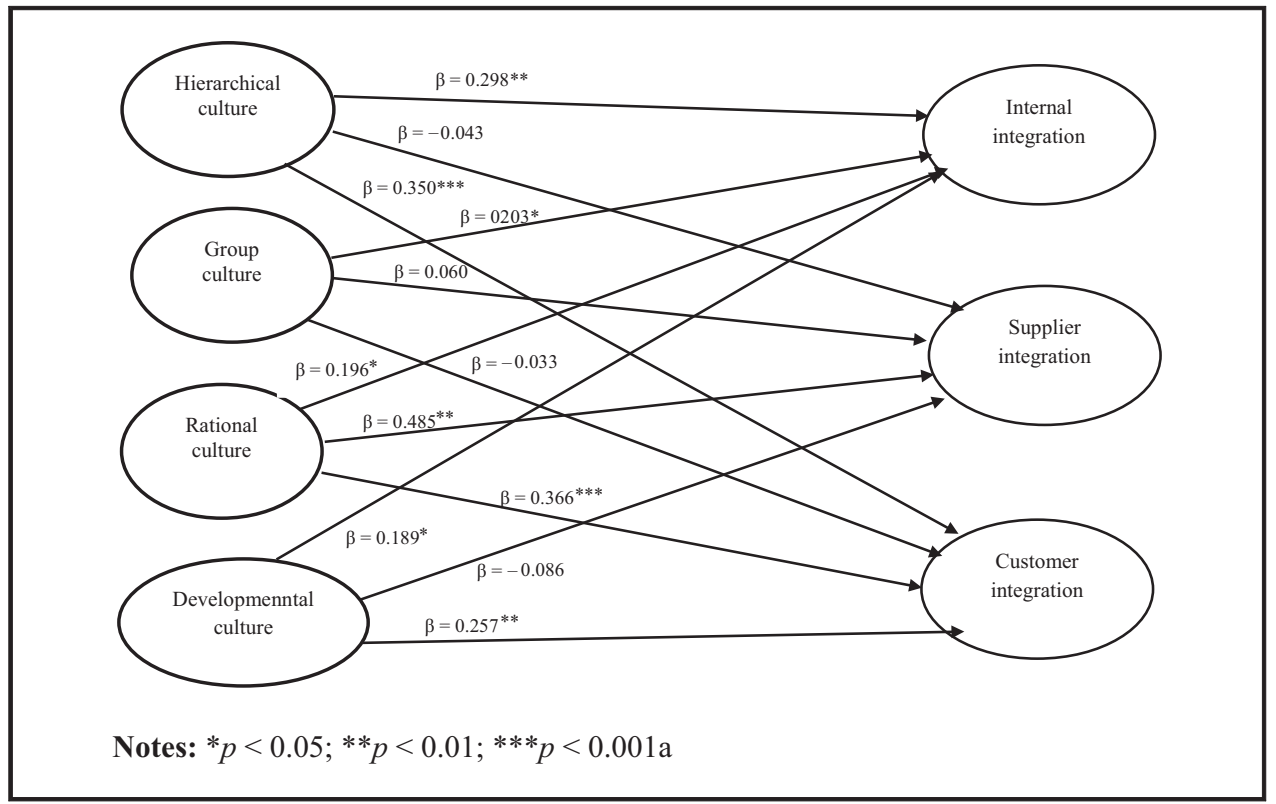

\section{Discussion}

According to Braunscheidel et al. (2010), the study of the impact of organizational culture on $\mathrm{SCl}$ has received limited attention in the literature. The purpose of this study is to analyze the impact of organizational culture, based on the CVF framework, on $\mathrm{SCl}$ in the hotel sector. The results reveal a direct link between organizational culture and SCl.

Before analyzing the results, it should be noted that an important factor that may influence the results of this study is that Egypt is considered an underdeveloped country and your culture is based on hierarchy and control. Therefore, all the hotels (whether chain hotels or independent) prefer to use the control strategy in their culture, meet predefined objectives and not fully involve employees and external suppliers in the business processes. According to the opinions of the managers surveyed in this study, this tendency could be due to the lack of employee qualifications or ability and, in the case of external suppliers, a lack of experience that leads to mistrust. However, there is a new tendency toward the external environment of the hotel, based on the use of innovation, understanding the external environment and sustainability. Thus, several hotels use control in their culture, but at the same time, they direct their resources toward the hotel's external environment.

Our findings suggest that rational culture is the most appropriate culture for SCl. The model shows that rational culture positively influences all three dimensions of SCl. The findings of this study are similar to those of other studies, but not exactly the same. The results of Braunscheidel et al. (2010) and Zu et al. (2010) suggest the positive impact of rational culture on external integration. In contrast, Cao et al. (2015) indicate that this culture significantly influences internal integration. This overall influence is due to the fact that the national culture of the destination favors the internal focus represented by internal aspects such as control and stability and at the same time, the external focus is oriented toward competitiveness and the achievement of predefined objectives through close relationships with suppliers and customers and contact with the external environment, which generate corporate profits and value for all parts of the supply chain. Hence, this result confirms the suitability of rational culture for implementing SCl. 
In addition, the results suggest the significant effect of the developmental culture on internal integration and customer integration. This result may fit the new trend toward innovation and contact with the external environment in Egyptian hotels. Our results are similar to those obtained in previous studies: Porter (2019), Cao et al. (2015) and Braunscheidel et al. (2010). Furthermore, these previous studies suggest a significant relationship between developmental culture and supplier integration, a result we did not find in our study. The findings indicate that there is no significant relationship between developmental culture and supplier integration (outsourcing providers in our case), perhaps, because hotels have not developed a close collaboration with the suppliers of the outsourced activities. Developmental culture focuses on product quality and meeting customer needs (Cameron and Quinn, 2011). According to Maelah et al. (2010) suggest that these external suppliers can cause the hotel to lose the strategic flexibility that is considered the basis of its development and innovation.

Other findings refer to the positive impact of hierarchical culture on internal integration and customer integration. These results are contrary to those of previous studies (Cao et al., 2015; Braunscheidel et al., 2010). This positive influence is due to the nature of the predominant culture in the Egyptian hotel sector, given that it encourages control, as the employees perform their tasks and activities according to prescribed standards and tools, which can help to achieve efficiency, error detection and process improvement. These elements, according to Yunus and Tadisina (2016), are important for achieving internal integration. Therefore, this culture has a significant influence on customer integration because it offers high-quality products and services. However, the results show that there is no significant link between hierarchical culture and supplier integration. This lack of significance could be due to the fact that this culture emphasizes control, whereas supplier integration could lead to loss of control, especially in the case of outsourcing providers.

In the case of group culture, the results show that this culture only has a positive influence on internal integration. In addition, the results suggest that there are no significant relationships between group culture and supplier and customer integration, a result that has been noted in previous studies. For example, Braunscheidel et al. (2010) and Zu et al. (2010) reported that this culture is not associated with external integration. These results could be due to the internal focus of this culture.

When comparing the results of this study to the findings of previous studies, they vary somewhat. This difference could be due to the type of industry addressed and the national culture. First, it has been noted that previous studies have been conducted in the manufacturing sector. Thus, the organizational culture and the degree of integration in the industrial sector may be different in the services sector. Second, according to Flynn et al. (2010), there is an important factor that influences the implementation and degree of SCl: the national culture. Therefore, national culture plays a key role in the operational efficiency of SCl practices (Wong et al., 2017) and the hotel's culture. In this case, Egypt is considered an underdeveloped country and its culture is characterized by control. Therefore, the most appropriate culture for $\mathrm{SCl}$ in this tourist destination is the rational culture, which has an external focus with an internal emphasis on control. This could explain the discrepancies with other previous studies.

\subsection{Academic and practical implications}

From an academic point of view, this is the first study in the hotel context to examine the influence of organizational culture on $\mathrm{SCl}$ and constitutes a solid theoretical framework for understanding the values of four types of organizational culture and their relationships with $\mathrm{SCl}$. The findings support previous research suggesting that organizational culture strongly influences SCl (Braunscheidel et al., 2010; Cao et al., 2015) and those cultural values should be aligned with strategies adopted to improve performance and achieve company goals. The results show that rational culture is the most appropriate for $\mathrm{SCl}$, perhaps, 
because Egyptian hotels prefer to use all their resources and capabilities to achieve their objectives and emphasize communications with customers while having control over these processes. Another interesting result is that both hierarchical culture and developmental culture have significant relationships with internal integration and customer integration. In the case of hierarchical culture, this result contradicts previous research (Braunscheidel et al., 2010; Cao et al., 2015) and may be due to the fact that this destination favors this culture. Moreover, group culture only influences internal integration, despite its progressive nature.

From a practical perspective, the results of this study offer various implications for hotels and professionals in the sector. First, this research provides a presentation of organizational culture that can help managers to assess their culture. Second, our findings provide managers with ideas about how $\mathrm{SCl}$ can be implemented from an organizational culture standpoint. Hence, managers who want to implement or improve their SCI must adapt their cultures to these strategies because changing the organizational culture to achieve full integration is not an easy task (Braunscheidel et al., 2010).

Therefore, this study provides managers with the necessary information about which culture is most appropriate for $\mathrm{SCl}$ (the rational culture due to the nature of this destination) and the relationship of each culture with $\mathrm{SCl}$. Based on the results of this study, managers can use the positive results of this study to create a joint culture, not only based on rational culture but also on other cultures such as group and developmental, to support long-term values of development and innovation and increase the spirit of teamwork and employee participation. Furthermore, it is important for the managers of this destination to create a collaborative culture that accepts external suppliers and gives them space to develop their work in the best possible way without using so much control.

\subsection{Limitations and future research}

Despite its contributions to the literature and practice, this study has some limitations that can lead to future studies. First, this study analyzes the direct impact of organizational culture on $\mathrm{SCl}$, without considering other mediating or moderating variables such as leadership, organizational structure or relational variables, such as trust, commitment and collaboration could be considered in future studies.

Second, this study only uses the PLS technique and the contingency approach, which is another limitation. Therefore, future research should use the covariance-based SEM and the potential common method variance and the configuration approach to divide the organizational culture into different profiles.

Third, SCl presents not only internal but also external cooperation. Therefore, the fit between the hotel's culture and the culture of its suppliers or customers should influence $\mathrm{SCl}$. This study did not analyze the culture of suppliers or customers. Future research could study these types of cultures and investigate their effects on SCl.

Finally, future research could also add new constructs to the structural model, such as organizational performance, competitive advantage or national culture, to build a more robust framework for the impact of organizational culture on SCI.

\section{References}

Beth, S., Burt, D.N., Copacino, W., Gopal, C., Lee, H.L., Lynch, R.P. and Morris, S. (2003), "Supply chain challenges. building relationships", Harvard Business Review, Vol. 81 No. 7, pp. 64-73.

Braunscheidel, M.J., Suresh, N.C. and Boisnier, A.D. (2010), "Investigating the impact of organizational culture on supply chain integration”, Human Resource Management, Vol. 49 No. 5, pp. 883-911. 
Cameron, K.S. and Quinn, R.E. (2011), Diagnosing and Changing Organizational Culture: Based on the Competing Values Framework, John Wiley and Sons. New York, NY.

Cao, Z., Huo, B., Li, Y. and Zhao, X. (2015), "The impact of organizational culture on supply chain integration: a contingency and configuration approach", Supply Chain Management: An International Journal, Vol. 20 No. 1, pp. 24-41.

Central Agency for Public Mobilization and Statistics - Egypt (CAPMAS) (2019), El Cairo, Egypt.

Choi, H.C.P., Blocher, J.D. and Gavirneni, S. (2008), "Value of sharing production yield information in a serial supply chain", Production and Operations Management, Vol. 17 No. 6, pp. 614-625.

Cohen, J. (1988), Statistical Power Analysis for the Behavioral Sciences, 2nd ed.: Erlbaum Hillsdale, NJ.

Dragan, D., Kramberger, T. and Topolsek, D. (2015), “"Supply chain integration and firm performance in the tourism sector", Pre-conference proceedings of the 12th International Conference on Logistics and Sustainable Transport, Celje, Slovenia.

El Houshy, S., Salem, I.E. and Agag, G. (2019), "The impact of perceived benefits and risks on current and desired levels of outsourcing: hotel managers' perspective", International Journal of Hospitality Management, Vol. 1.

Falk, R.F. and Miller, N.B. (1992), A Primer for Soft Modeling, University of Akron Press. Akron.

Flynn, B.B., Huo, B. and Zhao, X. (2010), "The impact of supply chain integration on performance: a contingency and configuration approach”, Journal of Operations Management, Vol. 28 No. 1, pp. 58-71.

Fornell, C. and Larcker, D.F. (1981), "Structural equation models with unobservable variablesand measurement error: algebra and statistics", Journal of Marketing Research, Vol. 18 No. 3, pp. 328-388.

Gambi, L.D.N., Boer, H., Gerolamo, M.C., Jørgensen, F. and Carpinetti, L.C.R. (2015), "The relationship between organizational culture and quality techniques, and its impact on operational performance", International Journal of Operations \& Production Management, Vol. 35 No. 10, pp. 1460-1484.

Hair, J.F., Hult, G.T.M., Ringle, C. and Sarstedt, M. (2017), A Primer on Partial Least Squares Structural Equation Modeling (PLS-SEM), Sage publications. Thousand Oaks, CA.

Henseler, J., Ringle, C.M. and Sarstedt, M. (2015), "A new criterion for assessing discriminant validity in variance-based structural equation modeling", Journal of the Academy of Marketing Science, Vol. 43 No. 1, pp. 115-135.

Maelah, R., Aman, A., Hamzah, N. and Amiruddin, R. (2010), "Accounting outsourcing turnback: process and issues", strategic outsourcing", An International Journal, Vol. 3 No. 3, pp. 226-245.

Mordorintelligence (2020), "Hospitality industry in Egypt - growth, trends, Covid-19 impact, and forecasts (2021-2026)", available at: www.mordorintelligence.com/industry-reports/hospitality-industry-in-egypt

Naor, M., Goldstein, S.M., Linderman, K.W. and Schroeder, R.G. (2008), "The role of culture as driver of quality management and performance: infrastructure versus core quality practices", Decision Sciences, Vol. 39 No. 4, pp. 671-702

Podsakoff, N.P. (2003), "Common method biases in behavioral research: a critical review of the literature and recommended remedies", Journal of Applied Psychology, Vol. 88 No. 5, pp. 879-903.

Porter, M. (2019), "Supply chain integration: does organizational culture matter?", Operations and Supply Chain Management: An International Journal, Vol. 12 No. 1, pp. 49-59.

Reuters (2020), "Egypt set to exceed 215,000 hotel rooms by end of 2021", available at: www.arabnews. com/node/1811656/business-economy

Ringle, C.M., Sarstedt, M., Mitchell, R. and Gudergan, S.P. (2018), "Partial least squares structural equation modeling in HRM research", The International Journal of Human Resource Management, Vol. 1, pp. 1-27.

Tenenhaus, M., Vinzi, V.E., Chatelin, Y.M. and Lauro, C. (2005), "PLS path modeling", Computational Statistics \& Data Analysis, Vol. 48 No. 1, pp. 159-205

Tepeci, M. and Bartlett, A.B. (2002), "The hospitality industry culture profile: a measure of individual values, organizational culture, and person-organization fit as predictors of job satisfaction and behavioral intentions", International Journal of Hospitality Management, Vol. 21 No. 2, pp. 151-170.

Wong, C.W., Sancha, C. and Thomsen, C.G. (2017), "A national culture perspective in the efficacy of supply chain integration practices", International Journal of Production Economics, Vol. 193, pp. 554-565. 
Yunus, E.N. and Tadisina, S.K. (2016), "Drivers of supply chain integration and the role of organizational culture", Business Process Management Journal, Vol. 22 No. 1, pp. 89-115.

Zhang, X., Song, H. and Huang, G.Q. (2009), "Tourism supply chain management: a new research agenda", Tourism Management, Vol. 30 No. 3, pp. 345-358.

Zhao, X., Huo, B., Flynn, B.B. and Yeung, J.H.Y. (2008), "The impact of power and relationship commitment on the integration between manufacturers and customers in a supply chain", Journal of Operations Management, Vol. 26 No. 3, pp. 368-388.

Zhao, X., Huo, B., Selen, W. and Yeung, J.H.Y. (2011), "The impact of internal integration and relationship commitment on external integration”, Journal of Operations Management, Vol. 29 No. 1-2, pp. 17-32.

Zu, X., Robbins, T.L. and Fredendall, L.D. (2010), "Mapping the critical links between organizational culture and TQM/six sigma practices", International Journal of Production Economics, Vol. 123 No. 1, pp. 86-106.

\section{Corresponding author}

Tomás F. Espino-Rodríguez can be contacted at: tomasfrancisco.espino@ulpgc.es

For instructions on how to order reprints of this article, please visit our website: www.emeraldgrouppublishing.com/licensing/reprints.htm

Or contact us for further details: permissions@emeraldinsight.com 